\title{
EMPREGO DE HERBICIDAS DO GRUPO DAS URÉIAS SUBSTITUIIDAS NA \\ CULTURA DA CENOURA (Daucus carota L.). I - CONTROLE DAS \\ PLANTAS DANINHAS
}

\author{
ANTONIO AUGUSTO LUCCHESI* \\ SALIM SIMĀO ** \\ KEIGO MINAMI **
}

RESUMO

Foi realizado no Campo Experimental do Setor de Horticultura da ESALQ, Piracicaba - SP, um experimento com a finalidade de verificar o efeito do linuron, cloroxuron e clorobromuron no controle de plantas daninhas na cultura da cenoura cv. "Kuroda". Foram testadas as dosagens mínima e máxima recomendadas pelos produtores dos herbicidas, em pré e pós-emergência das plantas daninhas.

O linuron, tanto em pré com em pós-emergência, foi o mais eficiente, e o clorobromuron também deu bons resultados. $\mathrm{O}$ menos eficiente foi o cloroxuron a $6 \mathrm{~kg} / \mathrm{ha}$ (dosagem mínima).

Os herbicidas não conseguiram impedir o desenvolvimento das plantas daninhas até o final da cultura, havendo necessidade de se aplicar, talvez, uma outra dosagem após 40 dias de semeadura de cenoura.

\section{INTRODUÇÃO}

No Brasil, a cenoura é mais cultivada nas regiōes sul e sudeste, notadamente no Estado de São Paulo.

A expansão da cultura da cenoura está sendo rápida e o que se nota é a extensão das áreas de cultivo nas novas regiões. Enquanto que os agricultores tradicionais cultivam pequenas áreas principalmente nos chamados cinturões verdes, os novos agricultores de cenoura cultivam áreas enormes, dando um caráter extensivo à cultura de cenoura.

A grande expansão da cultura de cenoura se deve ao aumento no consumo, estimando-se hoje em mais de 1.500 .000 caixas de 20 dúzias a produção no Estado de São Paulo.

Sendo uma cultura de semeadura direta, necessita de desbaste de mudas, sendo o principal problema a concorrência das plantas daninhas.

A cultura de cenoura exige um controle eficiente das plantas daninhas, principalmente nos estágios iniciais de desenvolvimento.

\footnotetext{
Entregue para publicação em 4/12/1975.

* Departamento de Botânica - ESALQ/USP.

** Departamento de Agricultura e Horticultura - ESALQ/USP.
} 
A utilização da capina apresenta o sério inconveniente de provocar ferimentos nas plantinhas, abrindo caminho para as doenças, além de encarecer a produção, devido ao custo elevado de mão-de-obra e não haver um controle eficiente de plantas daninhas, principalmente dentro da linha.

O herbicida vem substituindo a capina com grande sucesso, tendo o seu emprego aumentado muito na cultura da cenoura nos últimos tempos.

Sendo os herbicidas do grupo das uréias os mais recomendados para a cultura da cenoura, o presente trabalho tem por finalidade comparar os efeitos de alguns herbicidas deste grupo no controle das plantas daninhas, na cultura da cenoura.

\section{REVISÃO DA LITERATURA}

Inicialmente foram usados os óleos minerais derivados de petróleo no controle das plantas daninhas na eultura da cencura, devido à resistência das umbelíferas à ação tóxica dos óleos (LACHMAN, 1944; SWEET, RUNKEL e RALEIG, 1944; CRAFTS e REIBER, 1948; SANTOS, 1964).

Entretanto, o uso dos óleos minerais só é econômico nos países produtores de petróleo, não sendo o seu uso muito conveniente nos países importadores de petróleo. Além disso, há necessidade de se tranportar grandes quantidades de óleo para o campo, o que é um problema muito grande, devido às dificuldades tanto no transporte como no aumento no custo de aplicação.

Em virtude desses problemas, o emprego desses óleos foi dando lugar a outros herbicidas, entre os quais se sobressaem as uréias substituídas.

LEIDERMAN e KRAMER (1966) realizaram dois ensaios em condição de campo, utilizando vários herbicidas residuais além de alguns óleos minerais do tipo solvente, e obtiveram resultados satisfatórios com alguns do grupo das uréias substituídas.

FORSTER e DEUBER (1971) instalaram três ensaios com cenoura, variedade IAC-3-815, utilizando vários herbicidas de diferentes grupos químicos, e diferentes épocas de aplicaçâo, obtendo bons resultados, quando utilizaram herbicidas do grupo das uréias substituídas.

\section{MATERIAIS E MÉTODOS}

O experimento foi conduzido no Campo Experimental do Setor de Horticultura da ESALQ, em solo argiloso, rico em matéria orgânica e com perfeita drenagem.

A cultivar de cenoura usada no experimento foi a "Kuroda", cujas sementes foram desinfetadas com Arasan na proporção de 2,5 g do produto por quilo de semente. A porcentagem de germinação foi de $85 \%$, determinada em germinador de areia a $25{ }^{\circ} \mathrm{C}$. 
A cultura foi conduzida dentro das normas e técnicas recomendadas. Os desbastes foram feitos aos 25 e 45 dias após o plantio respectivamente, deixando um espaço de $4 \mathrm{~cm}$ entre plantas.

Para efeito de análise estatística, em todas as parcelas deixou-se um total de 60 plantas dentro das 2 linhas úteis.

$\mathrm{Na}$ condução do experimento foram utilizados 3 herbicidas do grupo das uréias substituídas, em 2 níveis de concentração: dosagens mínima e máxima do produto comercial, recomendadas pelos produtores.

Os herbicidas foram aplicados em 2 épocas: em pré e pós-emergência às plantas daninhas, com 3 repetições de cada tratamento.

Foram utilizados os seguintes herbicidas:

a - Linuroun, [3-(3,4-diclorofenil)-1-metoxi 1-metiluréia], pó molhável, com 50\% i.a.

b - Cloroxuron, [3-4(4-cloroferoxi)-fenil-1-dimetiluréia], pó molhável, com 50\% i.a.

c-Clorobromuron, [3-(4-bromo-3-clorofenil)-1-metoxi-1-metiluréia], pó molhável, com $50 \%$ i.a.

$\mathrm{O}$ experimento foi em delineamento inteiramente casualizado em parcelas subdivididas. Foram utilizados canteiros de 20 metros de comprimento por $1,80 \mathrm{~m}$ de largura, subdivididas em parcelas de $1,60 \mathrm{~m} \times 1,60 \mathrm{~m}$. O número total de parcelas foi de 48 . Dentro de cada parcela a área útil foi de $1,25 \mathrm{~m} \times 0,40 \mathrm{~m}$, ou seja, de $0,5 \mathrm{~m}^{2}$, distanciadas umas das outras de $1,20 \mathrm{~m}$.

Os tratamentos (dosagem de produto comercial), tanto em pré como em pós-emergência, foram os seguintes:

$\mathrm{L}_{1}=2 \mathrm{~kg} / \mathrm{ha}$ de linuron

$\mathrm{L}_{2}=4 \mathrm{~kg} / \mathrm{ha}$ de linuron

$\mathrm{B}_{1}=2 \mathrm{~kg} / \mathrm{ha}$ de clorobromuron

$\mathrm{B}_{2}=3 \mathrm{~kg} / \mathrm{ha}$ de clorobromuron

$\mathrm{C}_{1}=6 \mathrm{~kg} / \mathrm{ha}$ de cloroxuron

$\mathrm{C}_{2}=10 \mathrm{~kg} / \mathrm{ha}$ de cloroxuron

$\mathrm{L}=$ Testemunha no "limpo", sendo a retirada de mato feita manualmente.

$\mathrm{S}=$ Testemunha no "sujo", onde deixou-se o mato proliferar até o final do ciclo da cultura.

A aplicação em pós-emergência foi efetuada 20 dias após a semeadura, quando as plantas apresentavam cerca de 3 pares de folhas. A aplicação em pré-emergência foi efetuada no mesmo dia da semeadura.

Foram coletados dados sobre a infestação de mato, segundo períodos predeterminados, procedendo-se a contagem das plantas daninhas encontradas dentro de cada parcela do experimento, classificando-se dentro das espécies botânicas.

Nos canteiros utilizados para o tratamento de pré-emergência, as contagens foram efetuadas aos 20,40, 60 dias após a aplicação e no dia da colheita de ce toura. Nos canteiros utilizados para os tratamentos de pós-emergência, as contagens foram efetuadas 
no dia da aplicação dos herbicidas, aos 20 e 40 dias após a aplicação dos mesmos e no dia da colheita.

$\mathrm{Na}$ colheita das cenouras, as plantas daninhas foram arrancadas de cada parcela e submetidas à secagem em estufa de circulação de ar quente, à $60^{\circ} \mathrm{C}$, até peso constante, quando foram pesadas.

\section{RESULTADOS}

Os resultados do número de plantas daninhas encontradas nos tratamentos de pré-emergência se acham no Quadro 1; os resultados do número de plantas daninhas encontradas nos tratamentos de pós-emergência se acham no Quadro 2 e os resultados do peso da matéria seca do mato encontrado $\mathrm{em} \mathrm{g} / \mathrm{m}^{2}$ de canteiro, nos tratamentos de pré e pós-emergência se acham no Quadro 3.

\section{DISCUSSÃo}

a) Tratamentos de pré-emergência - Conforme consta do Quadro 1, aos 20 dias após a aplicação dos herbicidas em pré-emergência, a quantidade de mato nas parcelas tratadas com herbicidas foi pequena, quando comparada com as das parcelas deixadas no "sujo". Mesmo assim, as plantas daninhas que apenas estavam num estágio inicial de desenvolvimento, enquanto que nas parcelas no "sujo" mostravam-se mais desenvolvidas.

Com o decorrer do tempo, o efeito dos herbicidas foi reduzido. 0 início da emergência das plantas daninhas deu-se 12 dias após a semeadura, nas parcelas tratadas, e 4 dias após a semeadura nas parcelas deixadas no "sujo"

Houve menos incidência de plantas daninhas nos tratamentos com linuron $\left(\mathrm{L}_{2}\right.$ e $\mathrm{L}_{1}$ ); os tratamentos menos eficientes foram aqueles onde se aplicou dosagens mínimas de clorobromuron e cloroxuron $\left(\mathrm{B}_{1}\right.$ e $\left.\mathrm{C}_{1}\right)$.

b) Tratamentos de pós-emergência - Nas plantas daninhas, os herbicidas derivados da uréia penetram pelas raízes etranislocam-se rapidamente para as folhagens. Nas folhas, inibem a fotólise da água (reação de Hill), interrompendo a fotossíntese e, por conseguinte, a síntese de carboidratos. Além disso, interferem no metabolismo das proteínas, retarda a mitose nos meristemas apicais, produzem o esfacelamento dos núcleos e obstroem os vasos do xilema (CAMARGO et al., 1970).

$O$ herbicida que mostrou rapidamente o seu efeito quando aplicado em pós-emergência, foi o linuron; dois dias após a aplicação, o mato apresentava os primeiros indícios de morte, ou seja, início de clorose nas margens das folhas e murchamento gradual do ápice para a base. Nas parcelas tratadas com clorobromuron, esses sintomas apareceram 5 dias após a aplicação e nas tratadas com cloroxuron, 7 dias após.

$\mathrm{O}$ efeito dos herbicidas foi aumentado com o decorrer do tempo; mas, aos 40 dias após a aplicação, ou seja, 60 dias após a semeadura de cenoura, outras espécies de plantas daninhas iniciaram a sua emergência. 


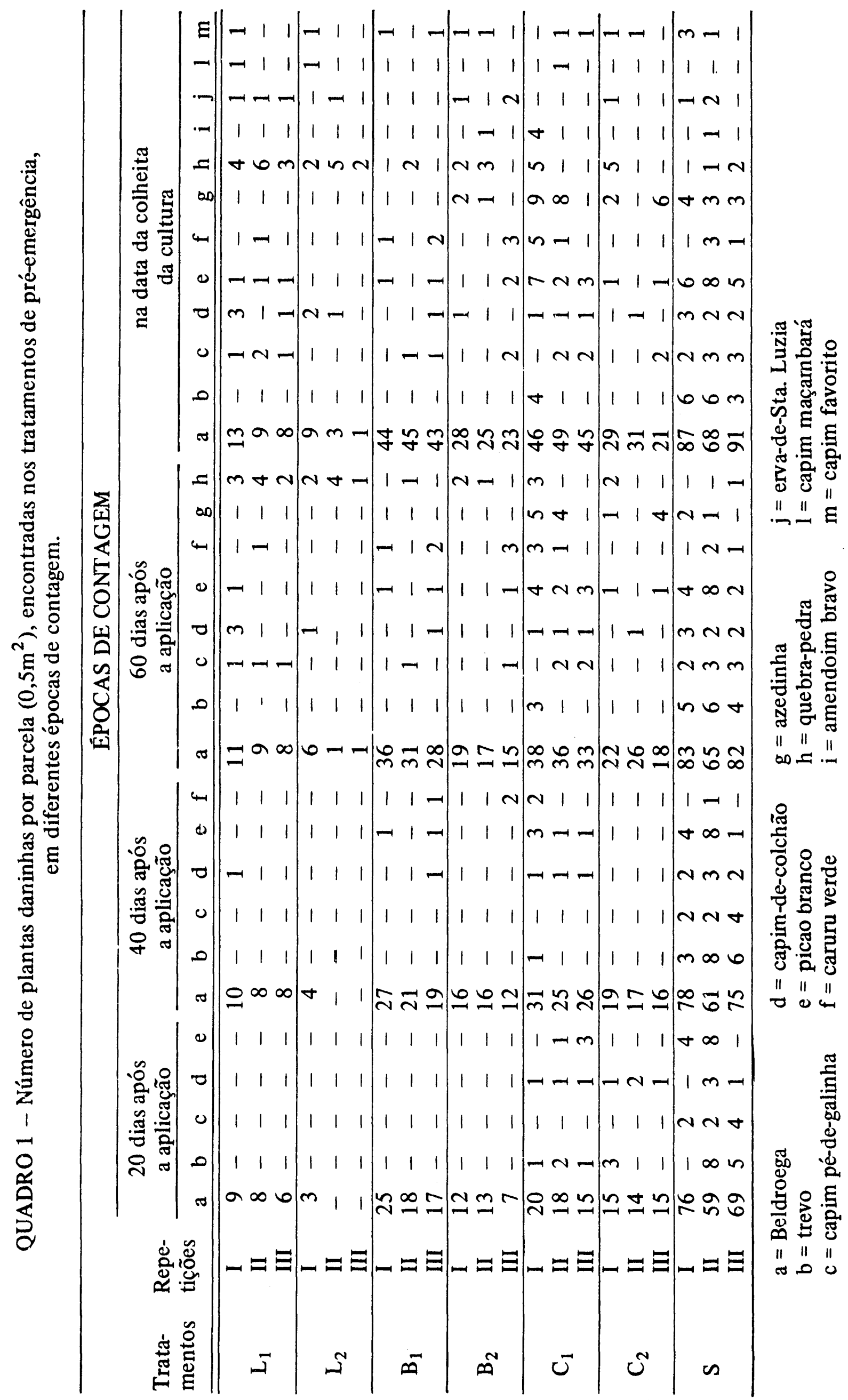




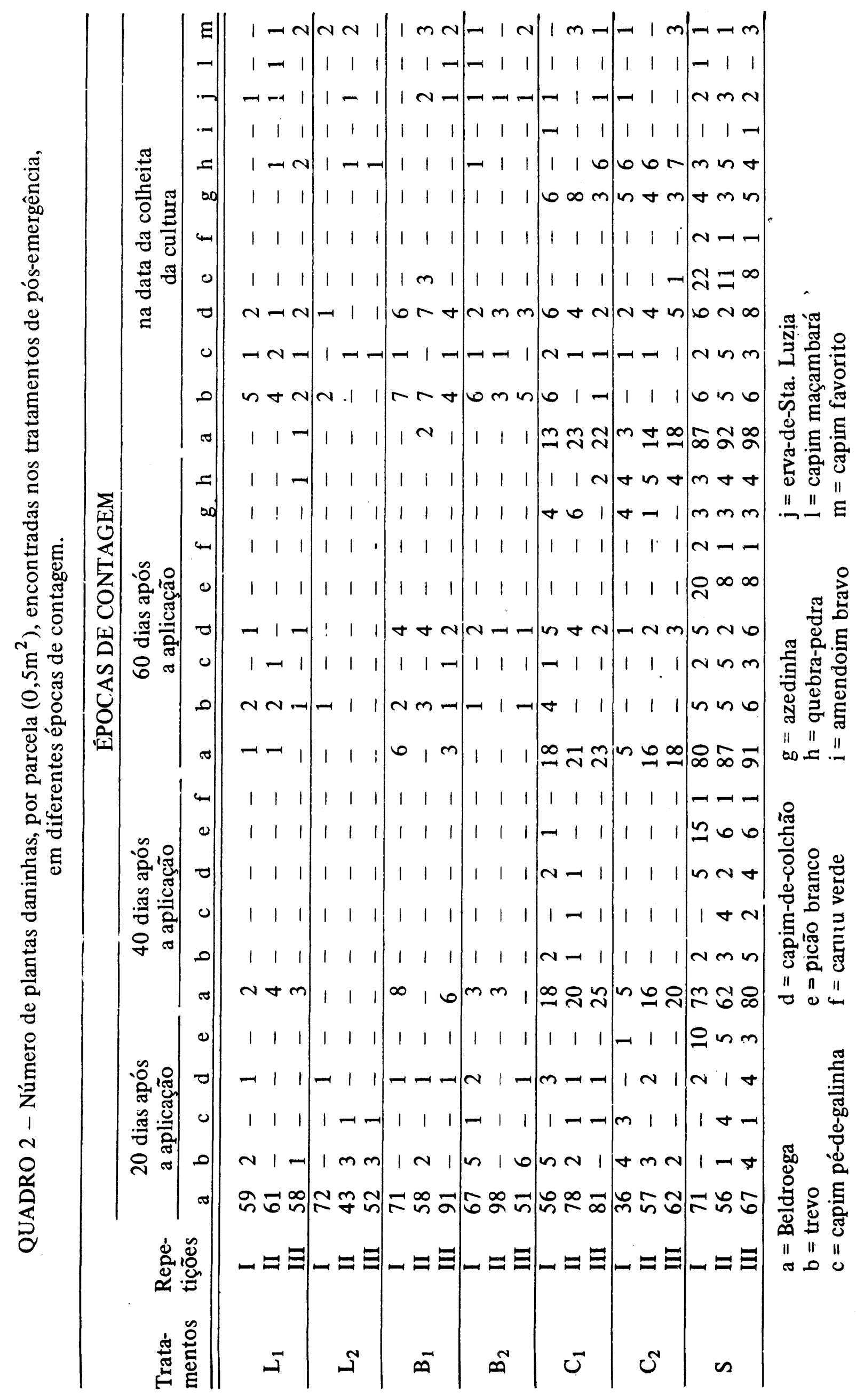


QUADRO 3 - Peso da matéria seca do mato encontrado em $\mathrm{g} / \mathrm{m}^{2}$ de canteiro, nos tratamentos de pré e pós-emergência.

\begin{tabular}{|c|c|c|c|c|c|c|}
\hline \multirow[t]{2}{*}{ Tratamentos } & \multicolumn{3}{|c|}{$\begin{array}{c}\text { Pré-Emergência } \\
\text { Répetição }\end{array}$} & \multicolumn{3}{|c|}{$\begin{array}{l}\text { Pós-Emergência } \\
\text { Repetição }\end{array}$} \\
\hline & I & II & III & I & II & III \\
\hline $\mathrm{L}_{1}$ & 256,6 & 265,6 & 221,0 & 137,0 & 161,0 & 315,6 \\
\hline $\mathrm{L}_{2}$ & 69,2 & 42,4 & 11,6 & 108,6 & 99,0 & 122,8 \\
\hline $\mathrm{B}_{1}$ & 722,4 & 245,0 & 414,6 & 225,0 & 365,4 & 443,0 \\
\hline$B_{2}$ & 522,6 & 376,4 & 456,8 & 245,0 & 312,6 & 276,8 \\
\hline $\mathrm{C}_{1}$ & 808,6 & 624,8 & 511,6 & 624,8 & 502,4 & 415,6 \\
\hline $\mathrm{C}_{2}$ & 383,0 & 704,2 & 347,4 & 503,0 & 480,4 & 437,0 \\
\hline 4 & 771,0 & 944,4 & 855,6 & 702,6 & 858,4 & 807,0 \\
\hline
\end{tabular}

D.M.S. $(5 \%)=209.91$ e C.V. $=26,88 \%$

Segundo o Quadro 2, houve menor infestação nas parcelas tratadas com linuron e com clorobromuron. $\mathrm{O}$ tratamento menos eficiente foi observado quando utilizou-se a dosagem mínima de Cloroxuron $\left(\mathrm{C}_{1}\right)$.

De acordo com o Quadro 3, verificou-se que o linuron controlou melhor as plantas daninhas e o tratamento menos eficiente foi quando utilizou-se a dosagem mínima de cloroxuron. Nas parcelas deixadas no "sujo", a proliferação do mato foi muito grande. Não houve diferença significativa entre as épocas de aplicação dos herbicidas. DEINDERMAN e KRAMER (1966) e FORSTER e DEUBER (1971) também obtiveram bons resultados com a utilização do herbicida linuron na cultura da cenoura.

\section{CONCLUSOES}

Dos resultados apresentados pode-se concluir que o controle mais eficiente das plantas daninhas, tanto em pré como em pós-emergência, foi obtido com o herbicida linuron. Obteve-se também, bons resultados com o clorobromuron. $O$ tratamento menos eficiente foi com o cloroxuron a $6 \mathrm{~kg} / \mathrm{ha}$.

Os herbicidas não conseguiram impedir o desenvolvimento das plantas daninhas até o final da cultura, havendo necessidade de se aplicar, talvez, uma outra dosagem após 40 dias de semeadura de cenoura. 


\section{USE OF SUBSTITUTED UREA HERBICIDES ON CARROT (Daucus carota L.) CROP. I - CONTROL OF WEEDS}

It was conducted in the Experimental Field of Horticulture Section of ESALQ, Piracicaba, an experiment to verify the effect of linuron, chloroxuron and chlorobromuron for weed control in carrot cv Kuroda. It was tested minimum and maximum rates recommended by herbicide productors in "pré" and post-emergence of weeds.

Linuron, in "pre"-and post-emergence, was more efficient and, chlorobromuron also gave good results. The less efficient was chloroxuron at $6 \mathrm{~kg} / \mathrm{ha}$ (minum rate).

The herbicides did not keep free of weeds until the end of carrot crop, maybe need another application after 40 days seedling.

\section{LITERATURA CITADA}

CAMARGO, P.N. de et al., 1971. Texto Básico de Controle Químico de Plantas Daninhas. ESALQ/ /USP, Piracicaba - SP. 3a ed. ampl. ilust., 431 pp.

CRAFTS, A.S. e H.G. REIBER, 1948. Herbicidal properties of oils. Hilgardia, Berkeley, U.S.A., 18(2):77-156.

FORSTER, R. e A. DEUBER, 1971. Comparação de herbicidas de diversos grupos químicos em Cenoura. XI Reunião Anual da Sociedade de Olericultura do Brasil, 11 a 17/julho, Piracicaba, $\mathrm{SP}$, resumo, $3 \mathrm{pp}$.

KOYAMA, I.Y.; Y. OKIMURA e N. MAKISHIMA, 1970. Hortaliças. IN: Guia de Comercialização Rural, São Paulo:152-164.

LACHMAN, W.H., 1964. The use of oil sprays as selective herbicides for carrots and parsnip. Amer. Soc. Hort. Sci. Proc., 45(445-448).

LEIDERMAN, L. e M. KRAMER, 1966. Controle de ervas daninhas em cenouras com herbicidas residuais. O Biológico, 32(3):43-48.

SANTOS, P. dos, 1965. Cenoura com herbicida dá maior rendimento. Divulgação Agronômica n? 14:12-13.

SWEET, R.D.; R. KUNKEL e G.J. RALEIG, 1964. Oil sprays for the control in carrotes and other vegetables (preliminary reports). Amer. Soc. Hort. Sci. Proc., 45:440-444. 